\title{
Protein interference for regulation of gene expression in plants
}

\author{
A.O. Vyacheslavova, I.A. Abdeeva, E.S. Piruzian, S.A. Bruskin 0
}

Vavilov Institute of General Genetics, RAS, Moscow, Russia

\begin{abstract}
Transcription factors (TFs) play a central role in the gene regulation associated with a plant's development and its response to the environmental factors. The work of TFs is well regulated at each stage of their activities. TFs usually consist of three protein domains required for DNA binding, dimerization, and transcriptional regulation. Alternative splicing (AS) produces multiple proteins with varying composition of domains. Recent studies have shown that AS of some TF genes form small proteins (small interfering peptide/small interfering protein, siPEP/siPROT), which lack one or more domains and negatively regulate target TFs by the mechanism of protein interference (peptide interference/protein interference, PEPi/PROTi). The presence of an alternative form for the transcription factor CCA1 of Arabidopsis thaliana, has been shown to be involved in the regulation of the response to cold stress. For the PtFLC protein, one of the isoforms was found, which is formed as a result of alternative splicing and acts as a negative repressor, binding to the full-length TF PtFLC and therefore regulating the development of the Poncirus trifoliata. For A. thaliana, a FLM gene was found forming the FLM- $\delta$ isoform, which acts as a dominant negative regulator and stimulates the development of the flower formation process due to the formation of a heterodimer with SVPTF. Small interfering peptides and proteins can actively participate in the regulation of gene expression, for example, in situations of stress or at different stages of plant development. Moreover, small interfering peptides and proteins can be used as a tool for fundamental research on the function of genes as well as for applied research for permanent or temporary knockout of genes. In this review, we have demonstrated recent studies related to siPEP/siPROT and their involvement in the response to various stresses, as well as possible ways to obtain small proteins.
\end{abstract}

Key words: peptide/protein interference (PEPi/PROTi); transcriptional factors; alternative splicing; small interfering peptide/protein (siPEP/siPROT); flowering time; circadian clock.

HOW TO CITE THIS ARTICLE:

Vyacheslavova A.O., Abdeeva I.A., Piruzian E.S., Bruskin S.A. Protein interference for regulation of gene expression in plants. Vavilovskii Zhurnal Genetiki i Selektsii = Vavilov Journal of Genetics and Breeding. 2018;22(7):756765. DOI 10.18699/VJ18.419

Received 13.04.2018

Accepted for publication 16.09 .2018

() AUTHORS, 2018

\section{Белковая интерференция как механизм регуляции экспрессии генов растений}

\author{
А.О. Вячеславова, И.А. Абдеева, Э.С. Пирузян, \\ С.А. Брускин $\otimes$
}

Институт общей генетики им. Н.И. Вавилова Российской академии наук, Москва, Россия

Транскрипционные факторы (ТФ) играют центральную роль в регуляционных процессах, связанных с развитием растений и их ответом на внешние воздействия. Работа ТФ регулируется на каждой стадии из активности. Как правило, ТФ состоят из трех доменов, необходимых для ДНК-связывания, димеризации и транскрипционной регуляции. Альтернативный сплайсинг позволяет получить множество белков с различным составом доменов. Недавние исследования показали, что в результате альтернативного сплайсинга некоторых генов, кодирующих ТФ, образуются малые пептиды (малые интерферирующие пептиды/белки, siPEP/ SiPROT), у которых отсутствует один или несколько доменов и которые негативно регулируют целевой ТФ благодаря механизму белковой интерференции (белковая/пептидная интерференция, PEPi/PROTi). Было показано наличие альтернативной формы для транскрипционного фактора CCA1 Arabidopsis thaliana, которая участвует в регуляции ответа на холодовой стресс. Для белка PtFLC обнаружена одна из изоформ, которая образуется в результате альтернативного сплайсинга и действует как негативный репрессор, связываясь с полноразмерным TФ PtFLC и тем самым регулируя некоторые стадии развития растения Poncirus trifoliata. Для A. thaliana обнаружен ген FLM, образующий изоформу FLM- $\delta$, которая работает как доминантный негативный регулятор и стимулирует процесс формирования цветка благодаря образованию гетеродимера с транскрипционным фактором SVP. Малые интерферирующие пептиды и белки могут быть активными участниками регуляции экспрессии генов, например, при стрессовых воздействиях или на разных стадиях развития растения. Более того, небольшие интерферирующие пептиды и белки могут быть использованы в качестве инструмента для фундаментальных исследований функции генов, а также в прикладных исследованиях, например, для временного или постоянного выключения гена. Данный обзор посвящен последним исследованиям, связанным с малыми интерферирующими пептидами и их ролью в ответе на различные стрессовые факторы, а также возможным путям получения малых интерферирующих пептидов.

Ключевые слова: пептидная интерференция (PEPi/PROTi); транскрипционные факторы; альтернативный сплайсинг; малые интерферирующие пептиды (siPEP/siPROT); период цветения; циркадные ритмы. 
$\mathrm{P}$ lants use different molecular mechanisms to respond to external abiotic and biotic factors for optimizing their growth and development in a changing environment. Most of the responses are based on the alterations of the expression levels of certain genes.

There are two main types of gene expression regulation negative and positive. In the case of positive regulation, the level of gene expression increases by the action of regulatory elements. On the other hand, with the help of other regulatory elements the level of gene expression can be reduced; this is called negative regulation.

Regulation of gene expression in a cell can usually performed at the transcriptional, translational, or protein levels. Negative regulation of transcription and translation can be accomplished by RNA interference (RNAi) (Vaucheret et al., 2001; Filipowicz et al., 2005; Sainsbury et al., 2015). However, even in the case of successful RNAi, there are already some transcripts of target genes accumulated in the cell. At the protein level, negative regulation is commonly accomplished by controlled ubiquitin-dependent proteolysis (Ingvardsen, Veierskov, 2001). This degradation pathway requires time to generate a response; this is critical when considering response to stress factors. Recently, a new pathway of transcriptional factor (TF) protein abundance regulation mediated by small proteins was discovered (Seo et al., 2011a). These small proteins were called "small interfering peptides/proteins" (siPEP/ siPROT) because of the similarity to the molecular mechanism of action of small interfering RNA (siRNAs). The siPROT's pathway was named "peptide/protein interference" (PEPi/ PROTi) similar to the RNAi.

TFs are the main players in the transcriptional control of a whole variety of plant genes, that are involved in plant growth and development as well as response to biotic and abiotic stresses. The activity of TFs can be regulated both at the synthesis step (transcription and translation) and by modifications of the synthesized protein molecule (i. e. by post-translational modifications) using different biochemical ways; for example, reversible phosphorylation, or nuclear-cytoplasmic localization are both post-translational modifications (Hill, 2015).

One of the main pathways for regulation of eukaryotic gene expression consists of controlling transportation of TFs from the cytoplasm into the nucleus. Some TFs in the cytoplasm are stored in a "dormant" state through physical association with cellular membranes. Such membrane-associated TFs (MTFs) are activated through controlled proteolytic cleavage and are then transferred to the nucleus. Cleavage can be affected by regulated intramembrane proteolysis (RIP) with a specific membrane-associated protease or by regulated ubiquitin/ proteasome-dependent processing (RUP) (Hoppe et al., 2001; Kim et al., 2007). In both cases, the process is controlled by biological signals targeting the membrane.

One known group of plant-specific TFs, regulated by RIP, is

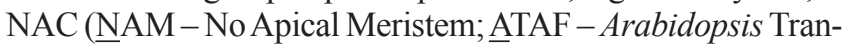
scription Activation Factor; $\underline{\mathrm{CUC}}-\mathrm{CUp}$-shaped Cotyledon), which plays an important role in the development processes in some plant species (Puranik et al., 2012). NAC proteins, including protein NTM1 (NAC with transmembrane motif 1) and related NAC members (e.g., NTM1-like), integrated into the ER (Endoplasmic Reticulum) or plasma membrane by the $\mathrm{C}$-terminal transmembrane domain, are released from the

\section{Abbreviations}

AS - Alternative splicing

bHLH - Basic helix-loop-helix transcription factor

CCA1 - CIRCADIAN CLOCK-ASSOCIATED1 protein

DELLA - domain which is required for $G A$ regulation,

named after the first five amino acids

DRM1/ARP - Dormancy-associated gene-1/Auxin-repressed protein

EE - Evening Element motif

ER - Endoplasmic reticulum

FLC - MADS-box protein FLOWERING LOCUS C

FLM - FLOWERING LOCUS M protein

FRI-FRIGIDA gene

GA - Gibberellin

GAI - Gibberellic acid insensitive protein

GRAS - family of plant-specific proteins, name comes

be the name of the first three members: GIBBERELLIC

ACID-INSENSITIVE (GAI), REPRESSOR of GAI (RGA),

and SCARECROW (SCR)

HDAC - Histone Deacetylases

HD-ZIP III - Class III homeodomain protein "leucine zipper"

HLH - Helix-loop-helix motif

HSP - Heat shock protein

IDD14 - INDERMINATE DOMAIN 14 transcriptional factor

gene

IDP - Intrinsically disordered protein

KDR - Kidari protein

MIF - "Mini zlnc Fingers" protein

MTFs - Membrane-associated TFs

NAC - NAM - No Apical Meristem; ATAF - Arabidopsis

Transcription Activation Factor; CUC - CUp-shaped

Cotyledon

PEPi/PROTi - Peptide interference/protein interference

PHB - Phabulosa, homeobox-leucine zipper protein

ATHB-14

PHV - Phavoluta protein, homeobox-leucine zipper

protein ATHB-9

PIFs - Phytochrome-interacting Factors

PsDRM1 - Pisum sativum DRM1 protein

PtFLC - Homolog of FLC in Poncirus trifoliata

QQS-QUA-QUINE STARCH gene

REV - Revoluta protein

RGA - Repressor of GAI

RIP - Regulated intramembrane proteolysis

RNAi - RNA interference

RUP - Regulated ubiquitin/proteasome-dependent

processing

SCR - Scarecrow protein

siPEP/siPROT - small interfering peptide/small interfering

protein

siRNA - small interfering RNA

STATs - Signal Transducers and Activators of Transcription

SVP - SHORT VEGETATIVE PHASE protein

TF - Transcriptional factor

ZF - "Zinc Finger" motif

ZHD - ZF-Homeodomain

ZPRs - Little zipper protein 


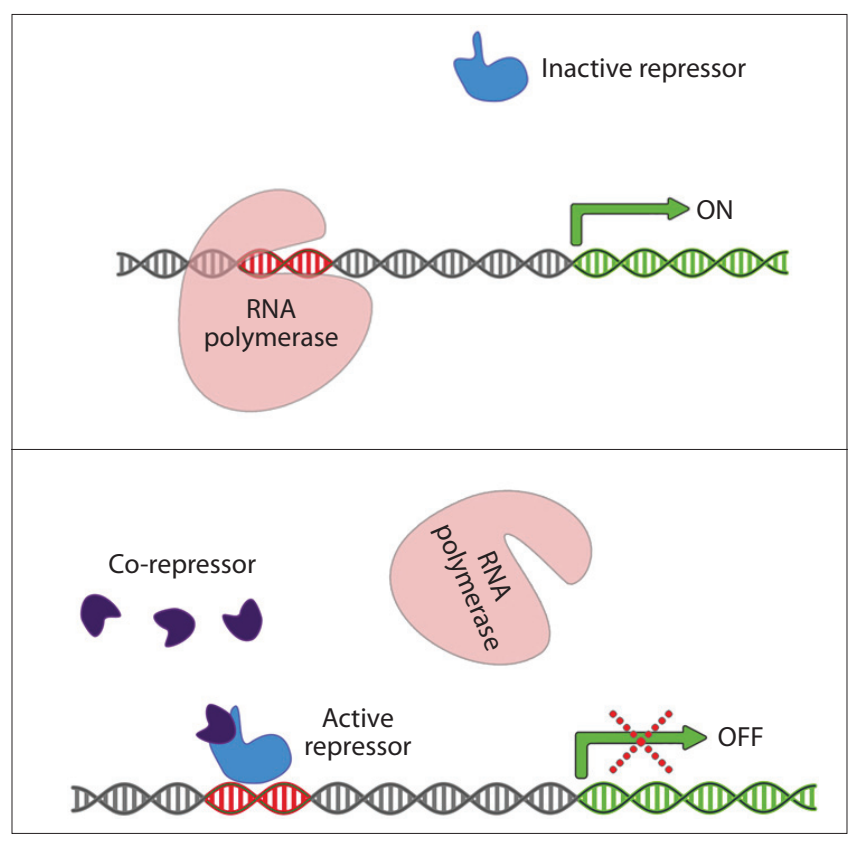

Fig. 1. A schematic representation of the mechanism of active repression. In the case of active repression, the repressor interacts with the regulatory region of the gene, thereby regulating the gene expression. The TFs can be a repressor that acts individually or by interacting with a corepressor protein, which has no DNA binding domain.

bound state by RIP. The activated NAC proteins are transferred to the nucleus, where they are involved in the transcriptional regulation of stress response genes, controlling time of flowering, germination ability of seeds, and other processes (Kim et al., 2006; Kim S.G. et al., 2008).

\section{Mechanisms of transcriptional repression: active and passive repression}

Eukaryotic organisms, including plants, have developed different mechanisms of transcriptional repression as a way to regulate gene expression. Generally, these mechanisms divided into two basic types: active and passive repression.

Active repression is based on the interaction between the repressor and DNA sequence in the regulatory region of the gene (Fig. 1).

Moreover, the repression domain of TFs interact with co-repressor proteins, which do not possess DNA binding domains (see Fig. 1). Co-repressor proteins control other regulators, such as chromatin remodeling factors that are involved in the formation of repressed chromatin sites. HDACs (histone deacetylases) are a good example of repressor proteins. They remove the acetyl group of a lysine residue in the histone tail and as a result, the chromatin is condensed, which usually leads to gene silencing (Shahbazian, Grunstein, 2007).

Under passive repression conditions the repressor does not interact directly with the DNA region but regulates other proteins indirectly through helper proteins. For example, gibberellin-mediated (GA-mediated) transcriptional regulation involves proteins from a subfamily of the plant-specific GRAS transcriptional regulators with the DELLA domain. After germination, Arabidopsis seeds are exposed to the day and night cycles. Hypocotyl elongation occurs by leaps and is dependent on the length of the dark period. During short photoperiod, maximum growth rate occurs in the dawn, then in the first hours of daylight the growth rate decreases (Nozue et al., 2007; Niwa et al., 2009). For example, hypocotyl elongation is significantly reduced when the germination of seedlings in constant daylight, which indicate the need of dark period (Soy et al., 2014). The elongation of hypocotyl in first hours of dawn involves the work of set of transcription factors from PIFs family (PIF1, PIF3, PIF4, PIF5) (Hug, Quail, 2002; Nozue et al., 2007; Niwa et al., 2009; Soy et al., $2012,2014)$. On the first step, in the end of the dark period the transcriptional level of PIF4 and PIF5 genes is increased (Nozue et al., 2007; Nusinow et al., 2011; Huang et al., 2012). At the same time the transcriptional levels of genes PIF1 and PIF3 remain practically constant throughout the light day (Soy et al., 2012, 2014). It is known that the proteins from phytochrome family interact with transcription factors from PIF family. This interaction leads to degradation TFs PIF1, PIF3, PIF4, PIF5 in a phytochrome-dependent manner (Bauer et al., 2004). According to this degradation in the first hours of the light period the level of proteins PIF1 and PIF3 is increased (Soy et al., 2014), and the level of PIF4 and PIF5 is optimized (Nozue et al., 2007; Yamashino et al., 2013). It was shown that PIFs are inactivated by DELLAs, which are not directly associated with the region of DNA, but instead with the PIFs DNA-recognition domain (Arana et al., 2011; Nieto et al., 2015); this effectively prevents PIFs from binding to the targeted DNA. Increasing GA level leads to association of GA and DELLA via GID1 receptor, and finally to the removal of PIFs repression and hypocotyl elongation (Fig. 2) (Feng et al., 2008).

\section{The discovery and characterization of siPEP/siPROT}

Recently, another mean of negative regulation of gene transcription in plants was discovered (Hu, Ma, 2006). One property of TFs is the ability to perform reversible formation of homo- and heterodimers. Most often, TFs form homodimers to increase their binding affinity to DNA. In some cases, TFs form heterodimers, where each monomeric TF protein have different degrees of DNA-binding affinity or specific transcriptional activity. The ability to form homo- and heterodimers is one of the regulatory mechanism characteristic of TFs and may possibly increase their variety (Klemm et al., 1998).

One example of the regulation of gene expression by heterodimers formation is a group of genes encoding small proteins (67-100 amino acid residues) with high homology to the TFs from Class III homeodomain proteins "leucine zipper" (HD-ZIP IIIs) has been found in A. thaliana genome (Wenkel et al., 2007; Kim Y.S. et al., 2008). These small proteins, named little zippers (ZPRs) have a unique structure compared to other known TFs because they have only the ZIP motif response for protein-protein interactions, but lack the DNAbinding and the $\mathrm{C}$-terminal activation domains. It is supposed that ZPR proteins are not functional TFs from the HD-ZIP IIIs family, but are able to form non-functional heterodimers with HD-ZIP IIIs TFs, thereby constituting an example of negative regulation of TFs (Fig. 3, a) (Wenkel et al., 2007). Generally, the HD-ZIP III TFs regulate vascular development, the activity of the shoot apical meristem and lateral organ patterning 


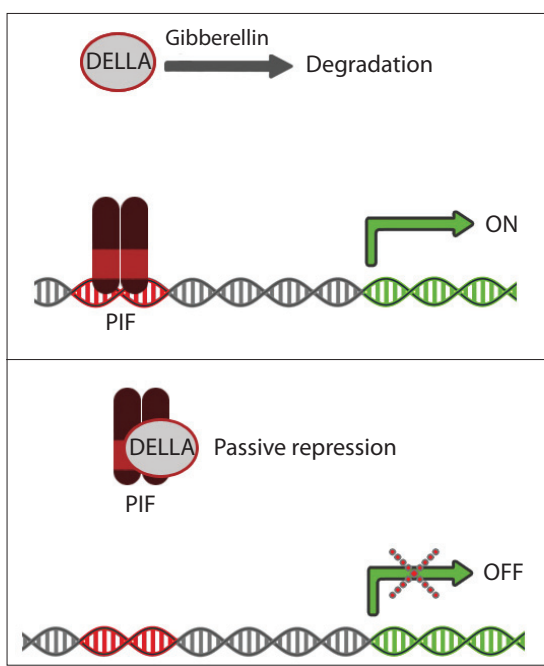

Fig. 2. A schematic representation of the passive repression of PIF transcription factors. In the case of passive repression, the repressor does not interact directly with the DNA region, but regulates other proteins indirectly through helper proteins. PIFs (phytochrome-interacting factors) are inactivated by proteins from a subfamily of the plant-specific GRAS transcriptional regulators with DELLA domain. DELLAs are not directly associated with the region of DNA, but instead with the PIFs bHLH DNA-recognition region and prevent binding of PIFs to the targeted DNA.

(Prigge et al., 2005). It has been shown that ZPR3 has specific association with the HD-ZIP III proteins, including ATHB15, ATHB8, Phabulosa (PHB), Phavoluta (PHV) and Revoluta (REV), using the ZIP motif (Kim Y.S. et al., 2008). Studies of protein-protein interactions and transcriptional activity showed that the ZPR-HD-ZIP III heterodimer is transcriptionally inactive because it does not bind with DNA (Wenkel et al., 2007). It is still unknown whether the ZPR-mediated transcriptional control is unique only to HD-ZIP IIIs or if "little zippers" could also regulate other TFs from different families.

Currently, investigation of structural organization of the ZPRs, their functional role and dominant-negative regulation of HD-ZIP IIIs TFs has led to the identification of some other similar proteins in the Arabidopsis genome (Seo et al., 2011a). An important specific characteristic of the new proteins was exclusion of one or more domains, for example DNA-binding or activation domains, but the presence of an intact dimerization domain. A small group of proteins, named "Mini zInc Fingers" (MIF) was also discovered. Like ZPR proteins, MIF

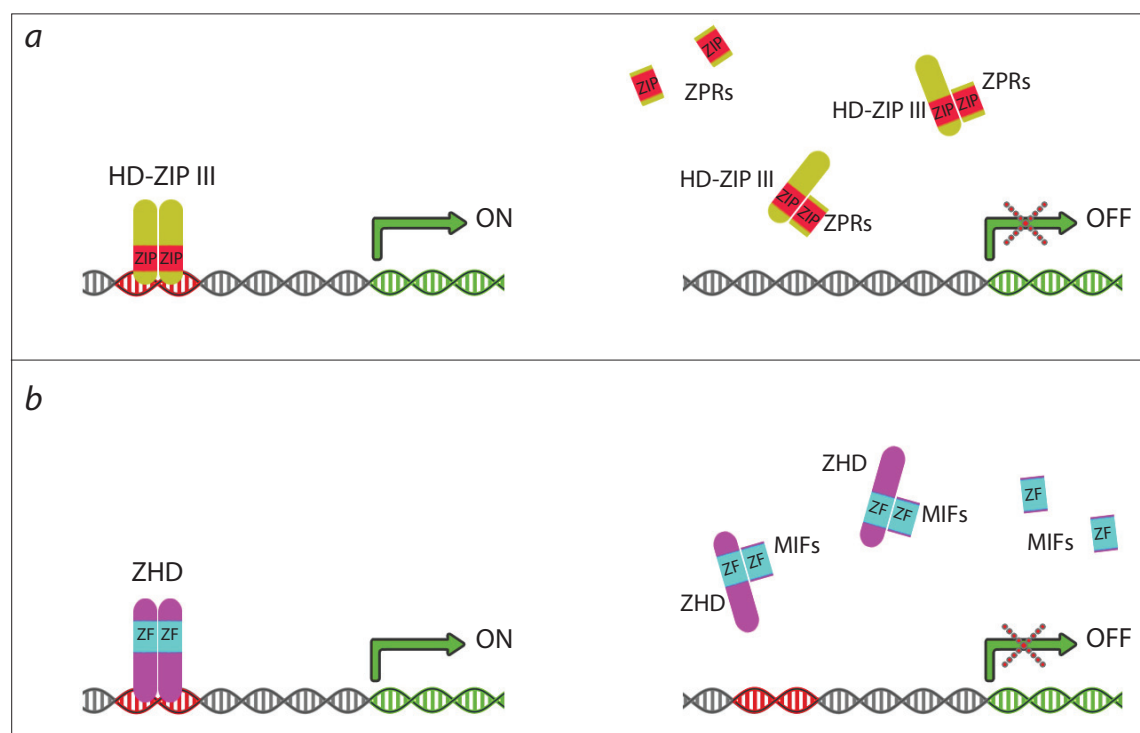

Fig. 3. Small plant proteins interact with transcription factors, thereby realizing negative regulation of a gene.

(a) Transcriptional factors from Class III homeodomain proteins "leucine zipper" (HD-ZIP IIIs) usually function as homodimers, but the truncated form of little zippers (ZPRs) leads to the formation of transcriptionally nonfunctional heterodimers. ZPRs have only the ZIP motif responsible for protein-protein interactions, but lack the DNA-binding and the C-terminal activation domains. (b) "Mini zlnc Fingers" (MIF) proteins do not have TF activities by themselves, but regulate the activities of the ZF-Homeodomain (ZHD) TFs by competitively forming nonfunctional heterodimers. MIF proteins contain a ZF motif that is highly homologous to the same motif within "Zinc Finger" of TF ZHD family, but lack the DNA-binding and the C-terminal activation domains.

proteins do not have TF activities by themselves, but regulate the activities of the ZF-Homeodomain (ZHD) TFs by competitively forming nonfunctional heterodimers (Hu, Ma, 2006; Hu et al., 2011). MIF small proteins contain a ZF ("Zinc Finger") motif that is highly homologous to the same motif within ZF of ZHD TF. On the other hand, MIFs do not have a DNA-binding HD motif, suggesting their involvement in negative regulation of ZHD TFs (Fig. 3, $b$ ).

Another example of small proteins is the Kidari (KDR) proteins that contain the helix-loop-helix (HLH) motif, which is highly homologous to a subgroup of the bHLH TFs. It has been shown that KDR proteins regulate the activity of HFR1, involved in plant photomorphogenesis (Hyun, Lee, 2006). HFR1 protein also plays an important regulatory role in plant response to sunlight (Zhang et al., 2008), and KDR proteins are important for signaling both the phytochrome A and cryptochromes (Duek, Fankhauser, 2003). So, the KDR-HFR1 interaction is responsible for blue and far-red light responses. The KDR protein consists of approximately 100 amino acid residues and has no activation domain, which is normally responsible for TF activity. KDR interacts with HFR1 through the HLH motif and prevents HFR1 from interacting with PIF transcription factors (Hyun, Lee, 2006; Hong et al., 2013).

As a result, discovered small proteins have been called "small interfering proteins/ peptides" (siPEP/siPROT), and their mechanism of action was named "peptide/ protein interference" (PEPi/PROTi) (Seo et al., 2011a, 2013).

\section{Alternative splicing as a way of producing siPEP/siPROT}

Another way of transcriptional regulation occurs via the formation of nonfunctional heterodimers. As it was shown recently by Seo (Seo et al., 2013), alternative splicing (AS)-derived protein isoforms act as dominant negative regulators via common to PEPi/PROTi mechanisms of nonfunctional heterodimer formation.

AS is a unique way to obtain different protein variants from one single gene in order to increase transcriptome diversity without drastically increasing the size of the genome of a eukaryotic organism. It has been shown that roughly $60 \%$ of all 
genes of plant genomes, containing introns, are alternatively spliced (Marquez et al., 2012). There is a view of the connection of the organism complexity and AS. AS may contribute to the development of an organism with a complex organization by increasing of the proteome diversity (Chen et al., 2014).

Many TF-encoding genes are involved in the regulation of various processes, such as flowering and stress response. Sometimes their transcripts are exposed to AS, that helps to regulate intracellular processes of adaptation. For example, TF IDD14, which regulates the metabolism of starch during cold stress, is exposed to AS (Seo et al., 2011b). In response to cold stress, a plant provides two spliced variants of $\mathrm{TF}$ IDD14: IDD14 $\alpha$, which is a full-sized version of the TF and IDD $14 \beta$ - a truncated variant of the TF with a damaged DNA-binding domain. It is important that TF IDD14 $\beta$ has a functional dimerization domain, which allows the formation of non-functional heterodimers consisting of truncated and the full-sized version of TF IDD14. It has been demonstrated that transgenic plants overexpressing IDD14 $\alpha$ only, have short growth. It is supposed that IDD14 $\alpha$ provides the influence on the QUA-QUINE STARCH (QQS) gene, involved in starch degradation. For transgenic plants overexpressing the $I D D 14 \beta$ gene only, the opposite was demonstrated: there was significant accumulation of starch in plant cells. Therefore, it could be reported that TF IDD14 $\beta$ plays a dominant-negative role in Arabidopsis plants (Seo et al., 2011b).

In the next parts of this review we will describe in more details several cases of the siPEP/siPROT-mediated regulation in plants.

\section{Regulation of plants genes expression using truncated forms of the TF protein}

\section{Circadian clock-associated 1 (CCA1) protein as a component of cold accommodation}

Genes involved in circadian rhythms of $A$. thaliana play an important role in the synchronization of a wide range of plant biological processes, and plant response to stress via transcriptome regulation. One of the key genes involved in the circadian rhythm of $A$. thaliana is $C C A 1$, encoding a Myb-related CCA1 transcription factor. The CCA1 TF participates in plant response to cold stress. It has been shown that transgenic plants expressing the $C C A 1$ gene demonstrate an improved resistance to low temperatures compared with plants harboring a mutation in this gene (Seo et al., 2012). In spite of the importance of CCA1, it is unknown how decreasing temperature influences activity of CCA1. It was shown that CCA1 is able to regulate gene expression by binding to EE (Evening Element) motif of target promoters regions. These motifs regulate the genes that are actively expressed in the evening (Harmer, 2009; Nagel et al., 2015). mRNA of CCA1 gene accumulates during dawn and represses the expression of target genes, accumulating in the evening. However, CCA1 protein levels decrease throughout the day, thus the expression levels of target genes which was suppressed previously increase and peaking in the evening (Alabadí et al., 2001). CCA1 plays an important role in regulating a large set of the biorhythmic transcriptome. Many of target genes include EE motif, but recently (Nagel et al., 2015) it was found a group of genes belonging to morning phase and enriched of unrecognized motifs associated with the function of CCA1.

Recently (Seo et al., 2012) it was shown that the CCA1 is capable of forming two splice variants: the full-sized functional protein $\mathrm{CCA} 1 \alpha$ and a truncated version - CCA $1 \beta$. CCA $1 \beta$ isoform has a full-sized dimerization domain that allows it to form homo/heterodimers, but it has no N-terminal MYB motif, which is involved in DNA binding. Consequently, CCA1 $\beta$ is able to form non-functional heterodimers with full-sized TF CCA1 $\alpha$ and also with TF LHY, which is involved in late elongation of hypocotyls and is also responsible for the plant's circadian rhythm. At low temperatures, CCA1 $\alpha$ is liberated from CCA $1 \beta$ and forms CCA $1 \alpha-C C A 1 \alpha$ and LHY-CCA $1 \alpha$ dimers, which bind to the $C B F$ gene promoters to induce freezing tolerance (Dong et al., 2011). Later it was shown that other genes involved in circadian rhythms of plants (TOC1, PRR3, PRR5, PRR 7 and PRR9), also have alternative splicing variants (Park et al., 2012).

\section{PtFLC protein responsible for control of flowering time}

Seasonal flowering of plants often requires pre-incubation at a low temperature. This phenomenon is known as vernalization and is observed for many plants, including A. thaliana. The vernalization period can continue for several weeks, compared to the influence of daylight duration, which is a trigger of the flowering process usually requiring just several days. Plants that require vernalization encode a repressor that blocks flowering during the summer or the fall periods.

Two key genes involved in the flowering process of $A$. thaliana are FLC and FRI. The FRI gene encodes supercoiled protein that is involved in transcription of the FLC gene, possibly through its effect on chromatin (Johanson et al., 2000). The FLC gene is a MADS-box TF, which is associated with genes involved in flowering, and blocks their transcription. FLC functions as a transcriptional repressor of flowering (Michaels, Amasino, 1999; Sheldon et al., 1999).

In Poncirus trifoliata, a homolog of FLC (Zhang et al., 2009) was also found. Gene expression of PtFLC is also regulated by temperature fluctuations. However, another regulation mechanism of the $P t F L C$ gene exists: it takes place on the post-transcriptional level by AS. PtFLC form 5 protein splice variants at various stages of plant development and under the influence of a particular temperature. The smallest isoform function as a negative repressor by competing for linkage to the DNA, or to form a non-functional heterodimer with full-sized PtFLC TF (Zhang et al., 2009). Perhaps, due to the need to regulate the development of the plant at different stages and at different temperatures, the PtFLC gene form 5 splice variants. This is one of the communication pathway between external signals and internal programming in plant development. Thus, the PtFLC1 and PtFLC 2 protein variants were found only in the developing tissues, while PtFLC4 and PtFLC5 isoforms were detected in already formed tissue of the adult plant. Isoforms of the PtFLC3 protein were detected at all stages of plant development. It is interesting that all of the alternative protein isoforms have the DNA-binding domain, but possess deletions of the C-terminal domain in different positions. However, the particular mechanism of action of PtFLC alternative isoforms is still not clear. 


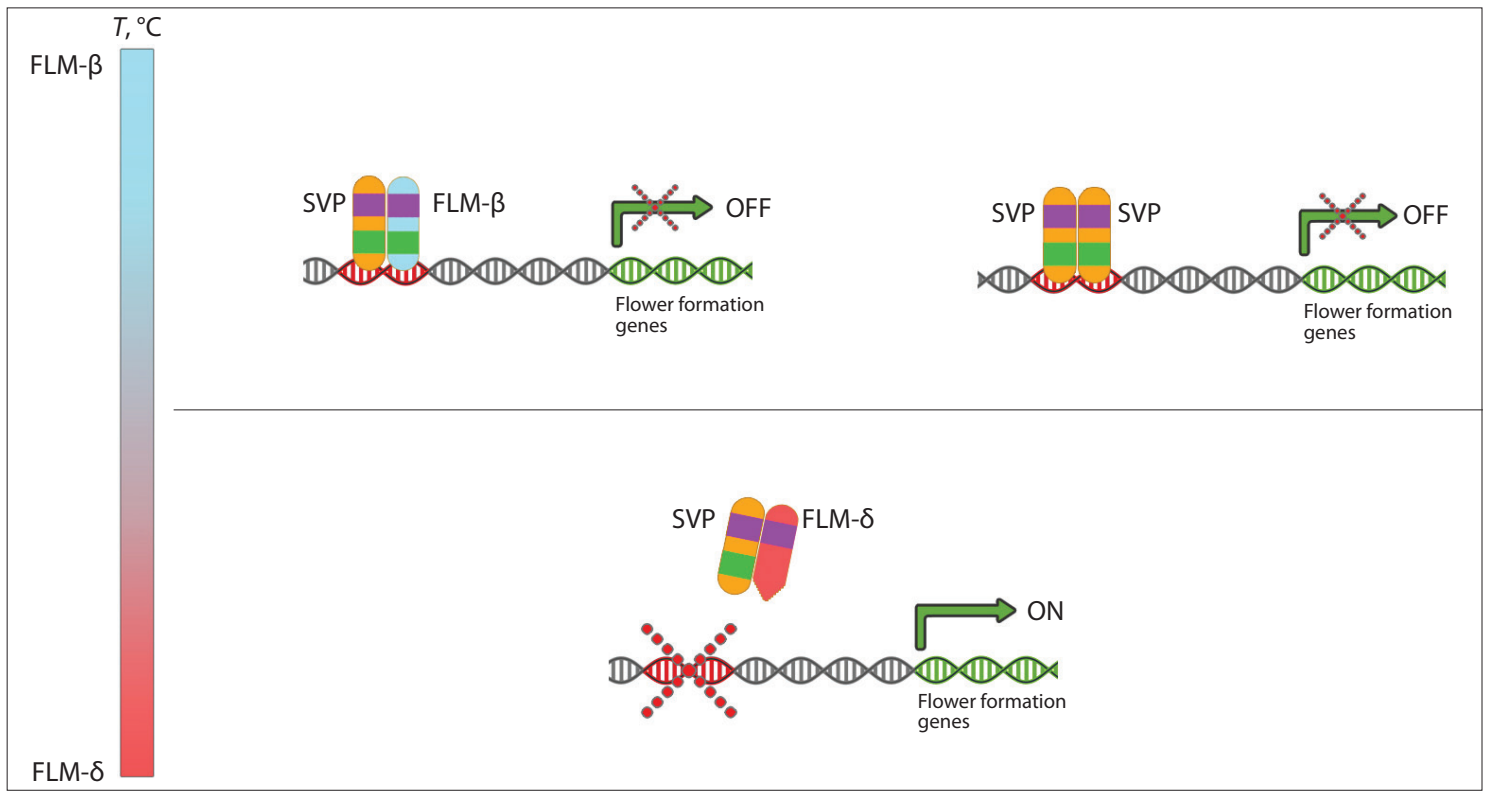

Fig. 4. The model of the SVP-FLM- $\delta$ and SVP-FLM- $\beta$ complex. In the case of a low temperature $\left(16{ }^{\circ} \mathrm{C}\right)$, the amount of FLM- $\beta$ proteins totals more than that of the FLM- $\delta$ splice isoform. Therefore, SVP could form homo- and heterodimers with TFs SVP and FLM- $\beta$, respectively. Heterodimer SVP-FLM- $\beta$ and homodimer SVP-SVP each connect to the regulatory regions of the genes controlling flower formation, thereby suppressing these genes, which causes delay of flowering. Increasing temperature $\left(27^{\circ} \mathrm{C}\right)$ forces the development of alternative protein isoforms - FLM- $\delta$ - that replace the FLM- $\beta$ isoforms in the heterodimer SVP-FLM- $\beta$.

\section{FLM- $\beta$ protein responsible for control of flowering time depending on the temperature}

As mentioned previously, the key mechanism of acceleration flowering of $A$. thaliana during prolonged cold exposure is associated with repression of FLC transcription factors, belonging to the MADS-box family (Song et al., 2012). To date, the phenomenon of vernalization in A. thaliana is studied well enough allowing the prediction of the existence of vernalization pathway in other plants based on their genotypes.

However, plant sensitivity to environmental temperature fluctuations is still under investigation (Verhage et al., 2014; Capovilla et al., 2015).

Important genes for flowering in A. thaliana are FLM and $S V P$. Proteins FLM and SVP are TFs that play an important role in flowering repression (Balasubramanian et al., 2006; Lee et al., 2007). Mutations in these genes account for the reduced sensitivity of plants to low temperatures, which indicate that FLM could act as a repressor of response to environmental temperature (Scortecci et al., 2001). It may be a result of the destruction of flowering-time regulation that depends on temperature (Balasubramanian et al., 2006; Lee et al., 2007; Gu et al., 2013).

It is known that RNA of the FLM gene is alternatively spliced generating the four isoforms of the protein. The most common are two isoforms: FLM- $\beta$ and FLM- $\delta$. It has been shown that FLM- $\beta$ isoforms predominate in cells of $A$. thaliana after cultivation at $16{ }^{\circ} \mathrm{C}$. However, at $23{ }^{\circ} \mathrm{C}$ both isoforms FLM- $\beta$ and FLM- $\delta$ - are produced in approximately the same quantities, and at $27{ }^{\circ} \mathrm{C}$ FLM- $\delta$ isoform predominates. As for the SVP gene, it was shown to be mostly independent of temperature (Posé et al., 2013). It has also been shown that the sole presence of the FLM- $\beta$ isoform in plant cells delay flowering, while existence of only the FLM- $\delta$ variant in the plant accelerates the flowering. In addition, both splice variants of the protein are able to form heterodimers with the SVP protein via the dimerization domain. Heterodimer SVP-FLM- $\beta$ bounds to the regulatory regions of genes controlling flower formation (SOC1, ATC, TEM2, SEP3, AP3, PI and others), thereby suppressing these genes and causing the delay of flowering. Moreover, the SVP protein form homodimers that repress the genes controlling formation of flowers. The heterodimer SVP-FLM- $\delta$ almost never binds to the regulatory regions of genes; this allows for transcription to occur. It seems that both isoforms compete with each other to build connection with the SVP protein. At low temperatures, the main product of the FLM gene is the FLM- $\beta$ protein, which blocks flower formation by development of the SVP-FLM- $\beta$ heterodimer. Increasing temperature forces the development of alternative protein isoforms - FLM- $\delta$ - that replaces the FLM- $\beta$ isoforms in the heterodimer SVP-FLM- $\beta$. Therefore, the FLM- $\delta$ isoform works as a dominant negative regulator and force the process of flower formation (Fig. 4) (Lee et al., 2013).

\section{Dormancy regulation and a role of DRM1 gene}

One process that influences plant growth and development in response to abiotic factors or endogenous biotic factors (e.g. hormonal regulators) is dormancy release. Dormancy can be determined as an absence of visible growth in meristematic plant tissue (Horvath et al., 2003). Endodormancy (winter dormancy) also exists in perennials and protects plants from external factors such as reduced light hours and extreme cold, as well as from the action of internal factors (e.g. hormones) at both the transcriptional and translational levels.

Dormancy-associated gene-1/Auxin-repressed protein $(D R M 1 / A R P)$ is often used as a genetic marker for dormant meristematic tissues (Rae et al., 2013). The functional role 


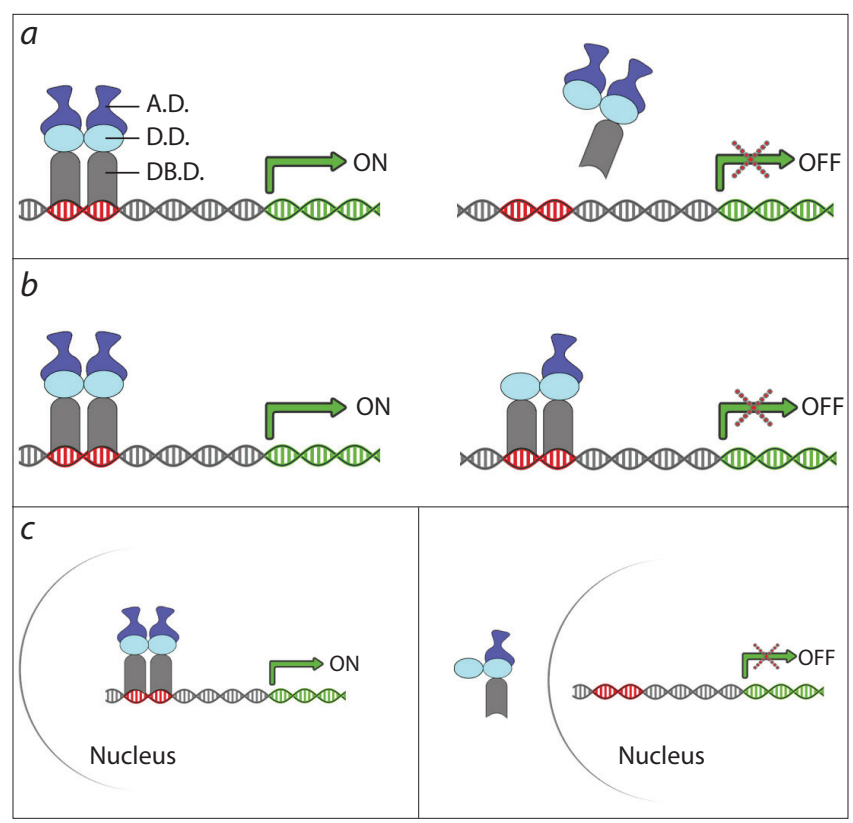

Fig. 5. Models of siPEP/siPROT action in plants.

A.D. - activation domain; D.D. - dimerization domain. DB.D. - DNA-binding domain.

(a) A siPEP/siPROT with dimerization and activation domains, but lacking a DNA-binding domain form heterodimers with a target TF. Such heterodimers will have reduced DNA-binding activity. (b) A siPEP/siPROT with DNA-binding and dimerization domains, but lacking an activation domain form heterodimers with a target TF. Such nonfunctional heterodimers have no transcriptional activity or have a reduced transcriptional activity compared to functional TF homodimers. (c) Isolation of target TFs from the nucleus by siPEP/siPROT.

of $D R M 1 / A R P$ was shown for the first time in pea (Stafstrom et al., 1998). It has been shown that the transcription level of PSDRM1 in dormant buds beneath the apex is high, but six hours after removal of the apex the transcriptional level of the gene falls significantly. Later, comparable profiles of expression were detected in $A$. thaliana plants (Tatematsu et al., 2005) and kiwifruit (Wood et al., 2013). The light signaling mutant, phyb, in Arabidopsis has a reduced, non-developing buds with a concomitant increase in DRMI/ARP expression (Kebrom et al., 2006). Perhaps other members of the DRM1/ $A R P$ family play an important role in response to different stress factors such as cold, salt stress, drought, and others.

AtDRM1 and DRM1 of kiwifruit, like many other genes involved in response to stress, undergo alternative splicing (Ner-Gaon et al., 2004). DRM1/ARP family members of kiwifruit have been supposedly classified as IDPs (Wood et al., 2013). These proteins have no stable tertiary structure, but can be packed partially depending on environmental conditions or interaction with other proteins; this effectively changes their physiological condition (Uversky, Dunker, 2010) and allows them to interact with a wide variety of protein-partner. It is interesting to note that many of IDPs in the isolated state create a strong connection with protein-partners. It was shown that these types of proteins are involved in the response to stress factors by associating with GRAS proteins (Sun et al., 2010, 2011) and heat shock proteins (Wang et al., 2004). However, the functional role of IDPs proteins is still not fully understood (Rangarajan et al., 2015). Recently, it was found that the AtDRM1 and AtDRM2 proteins can play a role as IDPs (Rae et al., 2014).

AtDRM1 has six alternatively spliced variants. While the AtDRM1.1-AtDRM1.5 splice variants demonstrated relatively conserved transcriptional response to different stresses, the AtDRM1.6 splice variant has a response to hormonal and salt stress (Ner-Gaon et al., 2004; Mastrangelo et al., 2012; Rae et al., 2014). Perhaps, due to the presence of alternative splicing for AtDRM1genes, as well as the ability to protein-protein interaction for IDPs, these proteins participate in regulating the response to abiotic stresses by protein-protein interaction.

\section{Models of siPEP/siPROT action}

To date, all the discovered small interfering proteins are characterized by small size (about 100 amino acid residues), and the obligatory presence of the domain responsible for dimerization or protein-protein interaction. Depending on other domains (for example, the DNA-binding domain or an activation domain) siPEP/siPROTs can be divided into two groups.

The first group includes siPEP/siPROTs with dimerization and an activation domain (Fig. 5, a). Such siPEP/siPROTs form a nonfunctional heterodimer with TFs to reduce DNAbinding affinity, negatively regulating the expression of genes and work as a passive repressor. Most siPEP/siPROTs are included in this group (as in ZPR and MIF proteins described above). This type of siPEP/siPROTs could also interact with TFs, acting as heterodimers with related TFs or other transcription regulators, such as DNA-binding factors.

The second group includes small proteins with dimerization and DNA-binding domains but missing an activation domain (Fig. 5, b). This type of siPEP/siPROTs develops a nonfunctional heterodimer with a TF and binds to DNA, but has no transcriptional activity or has a reduced transcriptional activity compared to functional TF homodimers (Seo et al., 2011a); thus, it acts as an active repressor.

Furthermore, heterodimer formation with siPEP/siPROTs can also taking out target TFs from the nucleus (Fig. 5, c). It was noticed for MIF protein that this group of proteins works in the "taking out from the nucleus" pathway. For example, nonfunctional heterodimer MIF-TF is excluded from the nucleus, such that it negatively regulates the work of the ZHD TFs (Hong et al., 2011).

Perhaps other ways of functional TF regulation by siPEP/ siPROTs could exist.

The siPEP/siPROT with a present DNA-binding domain, but missing the activation (required for transcriptional activation) and dimerization (for protein-protein interaction) domains would theoretically be able to compete with functional monomeric TFs for DNA binding. Moreover, the siPEP/ siPROT with the protein-binding domain that is involved in interactions with other proteins or cofactors could compete with functional TFs for binding with cofactors or other protein partners. This is required for TF activation. In addition, the siPEP/siPROTs with a DNA-binding domain only that form the nonfunctional homodimers siPEP/siPROT-siPEP/siPROT, would completely block the DNA binding sites for functional full-sized TFs. To date, these types of siPEP/siPROTs have not been yet identified, so the exact mechanism of regulation is difficult to predict. 


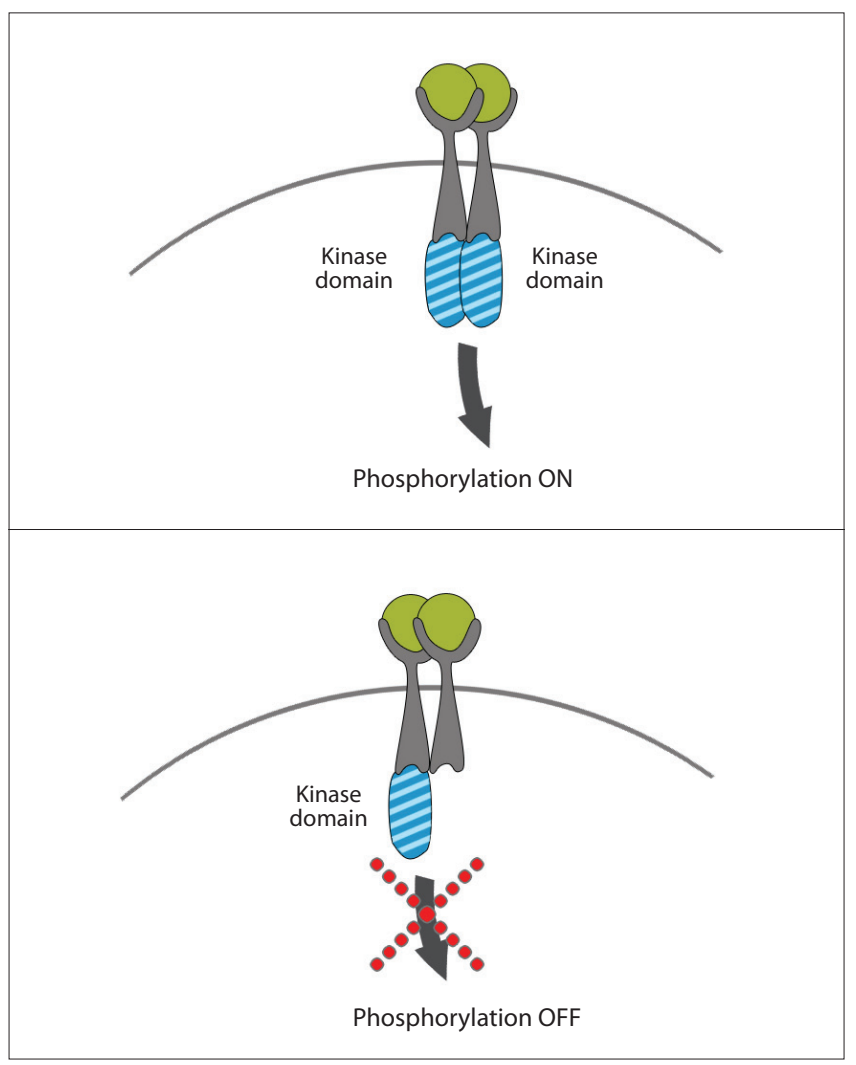

Fig. 6. Receptors could also form nonfunctional heterodimers due to lack of a domain (for example, kinase domain).

\section{Who can play the siPEP/siPROT role}

Small proteins can regulate the functional TFs by forming nonfunctional heterodimers, as well as by competing with them for DNA-binding sites. Despite some similarities to RNA interference, such as small molecular sizes and some missing biochemical activities, siPEP/siPROTs are distinct from siRNAs in that siPEP/siPROTs do not require any enzymatic stages for their action (except for the alternative splicing to generate them). The mechanism of small proteins' action is simple and easily predictable, which is useful for the creation of artificial siPEP/siPROTs for plant biotechnology.

Not only TFs, but also other proteins capable of forming dimers, e. g., receptors (including membrane), could utilize a similar mechanism of activity regulation by dimerization with small peptides/proteins (Fig. 6).

The PEPi/PROTi pathway could reduce the activity of such receptors. Moreover, the same approach could be applicable to all dimeric enzymes (e.g. acyl-ACP-thioesterase (Bhattacharjee et al., 2011), which control fatty acid deposition in seeds). This pathway plays a huge role in plant growth and developmental processes and responses to biotic and abiotic stresses as well.

Thus, small interfering peptides and proteins can actively participate in the regulation of gene expression, for example, in situations of stress or at different stages of plant development. Moreover, small interfering peptides and proteins can be used as a tool for fundamental research on the function of genes as well as for applied research for permanent or temporary knockout of genes.

\section{Acknowledgements}

Thanks are due to Marena Bartz for her critical comments and help in manuscript preparation.

This work was supported by the Russian Foundation for Basic Research (RFBR), grants number 14-04-31927-mol_a and 13-04-02197a.

This study was funded by the Presidium of the Russian Academy of Sciences, Program No. 41 "Biodiveristy of natural systems and biological resources of Russia".

\section{Conflict of interest}

The authors declare no conflict of interest.

\section{References}

Alabadí D., Oyama T., Yanovsky M.J., Harmon F.G., Más P., Kay S.A. Reciprocal regulation between TOC1 and LHY/CCA1 within the Arabidopsis circadian clock. Science. 2001;293(5531):880-883. DOI 10.1126/science.1061320.

Arana M.V., Marin-de la Rosa N., Maloof J.N., Blazquez M.A., Alabadí D. Circadian oscillation of gibberellin signaling in Arabidopsis. Proc. Natl. Acad. Sci. USA. 2011;108(22):9292-9297. DOI 10.1073/ pnas. 1101050108.

Balasubramanian S., Sureshkumar S., Lempe J., Weigel D. Potent induction of Arabidopsis thaliana flowering by elevated growth temperature. PLoS Genet. 2006;2(7):e106. DOI 10.1371/journal.pgen. 0020106.

Bauer D., Viczian A., Kircher S., Nobis T., Nitschke R., Kunkel T., Panigrahi K.C., Adam E., Fejes E., Schafer E., Nagy F. Constitutive Photomorphogenesis 1 and multiple photoreceptors control degradation of Phytochrome Interacting Factor 3, a transcription factor required for light signaling in Arabidopsis. Plant Cell. 2004;16(6): 1433-1445. DOI 10.1105/tpc.021568.

Bhattacharjee A., Ghosh S.K., Neogi K., Aich A., Willard B., Kinter M., Sen S.K., Ghosh D., Ghosh S. Deposition of stearate-oleate rich seed fat in Mangifera indica is mediated by a FatA type acyl-ACP thioesterase. Phytochemistry. 2011;72(2-3):166-177. DOI 10.1016/j. phytochem.2010.11.004.

Capovilla G., Schmid M., Posé D. Control of flowering by ambient temperature. J. Exp. Bot. 2015;66(1):59-69. DOI 10.1093/jxb/eru416.

Chen L., Bush S.J., Tovar-Corona J.M., Castillo-Morales A., UrrutiaA.O. Correcting for differential transcript coverage reveals a strong relationship between alternative splicing and organism complexity. Mol. Biol. Evol. 2014;31(6):1402-1413. DOI 10.1093/molbev/ msu083.

Dong M.A., Farré E.M., Thomashow M.F. CIRCADIAN CLOCK ASSOCIATED 1 and LATE ELONGATED HYPOCOTYL regulate expression of the C-REPEAT BINDING FACTOR (CBF) pathway in Arabidopsis. Proc. Natl. Acad. Sci. USA. 2011;108(17):7241-7246. DOI 10.1073/pnas.1103741108.

Duek P.D., Fankhauser C. HFR1, a putative bHLH transcription factor, mediates both phytochrome A and cryptochrome signaling. Plant J. 2003;34(6):827-836.

Feng S., Martinez C., Gusmaroli G., Wang Y., Zhou J., Wang F., Chen L., Yu L., Iglesias-Pedraz J.M., Kircher S., Schäfer E., Fu X., Fan L.M., Deng X.W. Coordinated regulation of Arabidopsis thaliana development by light and gibberellins. Nature. 2008;451(7177):475-479. DOI 10.1038/nature06448.

Filipowicz W., Jaskiewicz L., Kolb F.A., Pillai R.S. Post-transcriptional gene silencing by siRNAs and miRNAs. Curr. Opin. Struct. Biol. 2005;15(3):331-341. DOI 10.1016/j.sbi.2005.05.006.

Gu X., Le C., Wang Y., Li Z., Jiang D., Wang Y., He Y. Arabidopsis FLC clade members form flowering-repressor complexes coordinating responses to endogenous and environmental cues. Nat. Commun. 2013;4:1947. DOI 10.1038/ncomms2947.

Harmer S.L. The circadian system in higher plants. Annu. Rev. Plant Biol. 2009;60:357-377. DOI 10.1146/annurev.arplant.043008.092054. 
Hill K. Post-translational modifications of hormone-responsive transcription factors: the next level of regulation. J. Exp. Bot. 2015; 66(16):4933-4945. DOI 10.1093/jxb/erv273.

Hong S.Y., Kim O.K., Kim S.G., Yang M.S., Park C.M. Nuclear import and DNA binding of the ZHD5 transcription factor is modulated by a competitive peptide inhibitor in Arabidopsis. J. Biol. Chem. 2011;286(2):1659-1668. DOI 10.1074/jbc.M110.167692.

Hong S.Y., Seo P.J., Ryu J.Y., Cho S.H., Woo J.C., Park C.M. A competitive peptide inhibitor KIDARI negatively regulates HFR1 by forming nonfunctional heterodimers in Arabidopsis photomorphogenesis. Mol. Cells. 2013;35(1):25-31. DOI 10.1007/s10059-0132159-2.

Hoppe T., Rape M., Jentsch S. Membrane-bound transcription factors: regulated release by RIP or RUP. Curr. Opin. Cell Biol. 2001; 13(3):344-348.

Horvath D.P., Anderson J.V., Chao W.S., Foley M.E. Knowing when to grow: signals regulating bud dormancy. Trends Plant Sci. 2003; 8(11):534-540. DOI 10.1016/j.tplants.2003.09.013.

Hu W., Feng B., Ma H. Ectopic expression of the Arabidopsis MINI ZINC FINGER1 and MIF3 genes induces shoot meristems on leaf margins. Plant Mol. Biol. 2011;76(1-2):57-68. DOI 10.1007/s11103011-9768-y.

$\mathrm{Hu}$ W., Ma H. Characterization of a novel putative zinc finger gene MIF1: involvement in multiple hormonal regulation of Arabidopsis development. Plant J. 2006;45(3):399-422. DOI 10.1111/j.1365313X.2005.02626.x.

Huang W., Pérez-García P., Pokhilko A., Millar A.J., Antoshechkin I., Riechmann J.L., Mas P. Mapping the core of the Arabidopsis circadian clock defines the network structure of the oscillator. Science. 2012;336(6077):75-79. DOI 10.1126/science.1219075.

Huq E., Quail P.H. PIF4, a phytochrome-interacting bHLH factor, functions as a negative regulator of phytochrome B signaling in $\mathrm{Ara}$ bidopsis. EMBO J. 2002;21(10):2441-2450. DOI 10.1093/emboj/ 21.10.2441.

Hyun Y., Lee I. KIDARI, encoding a non-DNA binding bHLH protein, represses light signal transduction in Arabidopsis thaliana. Plant Mol. Biol. 2006;61(1-2):283-296. DOI 10.1007/s11103-006-0010-2.

Ingvardsen C., Veierskov B. Ubiquitin- and proteasome-dependent proteolysis in plants. Physiol. Plant. 2001;112(4):451-459.

Johanson U., West J., Lister C., Michaels S., Amasino R., Dean C. Molecular analysis of FRIGIDA, a major determinant of natural variation in Arabidopsis flowering time. Science. 2000;290(5490): 344-347.

Kebrom T.H., Burson B.L., Finlayson S.A. Phytochrome B represses Teosinte Branchedl expression and induces sorghum axillary bud outgrowth in response to light signals. Plant Physiol. 2006;140(3): 1109-1117. DOI 10.1104/pp.105.074856.

Kim S.G., Lee A.K., Yoon H.K., Park C.M. A membrane-bound NAC transcription factor NTL8 regulates gibberellic acid-mediated salt signaling in Arabidopsis seed germination. Plant J. 2008;55(1):7788. DOI 10.1111/j.1365-313X.2008.03493.x.

Kim S.Y., Kim S.G., Kim Y.S., Seo P.J., Bae M., Yoon H.K., Park C.M. Exploring membrane-associated NAC transcription factors in Arabidopsis: implications for membrane biology in genome regulation. Nuceic Acids Res. 2007;35(1):203-213. DOI 10.1093/nar/ gk11068.

Kim Y.S., Kim S.G., Lee M., Lee I., Park H.Y., Seo P.J., Jung J.H., Kwon E.J., Suh S.W., Paek K.H., Park C.M. HD-ZIP III activity is modulated by competitive inhibitors via a feedback loop in Arabidopsis shoot apical meristem development. Plant Cell. 2008;20(4): 920-933. DOI 10.1105/tpc.107.057448.

Kim Y.S., Kim S.G., Park J.E., Park H.Y., Lim M.H., Chua N.H., Park C.M. A membrane-bound NAC transcription factor regulates cell division in Arabidopsis. Plant Cell. 2006;18(11):3132-3144. DOI 10.1105/tpc.106.043018.

Klemm J.D., Schreiber S.L., Crabtree G.R. Dimerization as a regulatory mechanism in signal transduction. Annu. Rev. Immunol. 1998;16: 569-592. DOI 10.1146/annurev.immunol.16.1.569.
Lee J.H., Ryu H.S., Chung K.S., Posé D., Kim S., Schmid M., Ahn J.H. Regulation of temperature-responsive flowering by MADS-box transcription factor repressors. Science. 2013;342(6158):628-632. DOI $10.1126 /$ science. 1241097 .

Lee J.H., Yoo S.J., Park S.H., Hwang I., Lee J.S., Ahn J.H. Role of SVP in the control of flowering time by ambient temperature in Arabidopsis. Genes Dev. 2007;21(4):397-402. DOI 10.1101/gad.1518407.

Marquez Y., Brown J.W., Simpson C., Barta A., Kalyna M. Transcriptome survey reveals increased complexity of the alternative splicing landscape in Arabidopsis. Genome Res. 2012;22(6):1184-1195. DOI 10.1101/gr.134106.111.

Mastrangelo A.M., Marone D., Laidò G., De Leonardis A.M., De Vita P. Alternative splicing: enhancing ability to cope with stress via transcriptome plasticity. Plant Sci. 2012;185-186:40-49. DOI 10.1016/ j.plantsci.2011.09.006.

Michaels S.D., Amasino R.M. FLOWERING LOCUS C encodes a novel MADS domain protein that acts as a repressor of flowering. Plant Cell. 1999;11(5):949-956.

Nagel D.H., Doherty C.J., Pruneda-Paz J.L., Schmitz R.J., Ecker J.R., Kay S.A. Genome-wide identification of CCA1 targets uncovers an expanded clock network in Arabidopsis. Proc. Natl. Acad. Sci. USA. 2015;112(34):E4802-E4810. DOI 10.1073/pnas.1513609112.

Ner-Gaon H., Halachmi R., Savaldi-Goldstein S., Rubin E., Ophir R., Fluhr R. Intron retention is a major phenomenon in alternative splicing in Arabidopsis. Plant J. 2004;39(6):877-885. DOI 10.1111/j. 1365-313X.2004.02172.x.

Nieto C., López-Salmerón V., Davière J.M., Prat S. ELF3-PIF4 interaction regulates plant growth independently of the evening complex. Curr. Biol. 2015;25(2):187-193. DOI 10.1016/j.cub.2014.10.070.

Niwa Y., Yamashino T., Mizuno T. The circadian clock regulates the photoperiodic response of hypocotyl elongation through a coincidence mechanism in Arabidopsis thaliana. Plant Cell Physiol. 2009; 50(4):838-854. DOI 10.1093/pcp/pcp028.

Nozue K., Covington M.F., Duek P.D., Lorrain S., Fankhauser C., Harmer S.L., Maloof J.N. Rhythmic growth explained by coincidence between internal and external cues. Nature. 2007;448(7151):358361. DOI $10.1038 /$ nature 05946

Nusinow D.A., Helfer A., Hamilton E.E., King J.J., Imaizumi T., Schultz T.F., Farré E.M., Kay S.A. The ELF4-ELF3-LUX complex links the circadian clock to diurnal control of hypocotyl growth. Nature. 2011;475(7356):398-402. DOI 10.1038/nature10182.

Park M.J., Seo P.J., Park C.M. CCA1 alternative splicing as a way of linking the circadian clock to temperature response in Arabidopsis. Plant Signal Behav. 2012;7(9):1194-1196. DOI 10.4161/psb.21300.

Posé D., Verhage L., Ott F., Yant L., Mathieu J., Angenent G.C., Immink R.G., Schmid M. Temperature-dependent regulation of flowering by antagonistic FLM variants. Nature. 2013;503(7476):414-417. DOI 10.1038/nature12633.

Prigge M.J., Otsuga D., Alonso J.M., Ecker J.R., Drews G.N., Clark S.E. Class III homeodomain-leucine zipper gene family members have overlapping, antagonistic, and distinct roles in Arabidopsis development. Plant Cell. 2005;17(1):61-76. DOI 10.1105/tpc.104.026161.

Puranik S., Sahu P.P., Srivastava P.S., Prasad M. NAC proteins: regulation and role in stress tolerance. Trends Plant Sci. 2012;17(6):369381. DOI 10.1016/j.tplants.2012.02.004.

Rae G.M., David K.M., Wood M. The dormancy marker DRMI/ARP associated with dormancy but a broader role in planta. Dev. Biol. J. 2013:632524. DOI 10.1155/2013/632524.

Rae G.M., Uversky V.N., David K., Wood M. DRM1 and DRM2 expression regulation: potential role of splice variants in response to stress and environmental factors in Arabidopsis. Mol. Genet. Genomics. 2014;289(3):317-332. DOI 10.1007/s00438-013-0804-2.

Rangarajan N., Kulkarni P., Hannenhalli S. Evolutionarily conserved network properties of intrinsically disordered proteins. PLoS One. 2015;10(5):e0126729. DOI 10.1371/journal.pone.0126729.

Sainsbury S., Bernecky C., Cramer P. Structural basis of transcription initiation by RNA polymerase II. Nat. Rev. Mol. Cell. Biol. 2015; 16(3):129-143. DOI 10.1038/nrm3952. 
Scortecci K.C., Michaels S.D., Amasino R.M. Identification of a MADS-box gene, FLOWERING LOCUS M, that represses flowering. Plant J. 2001;26(2):229-236.

Seo P.J., Hong S.Y., Kim S.G., Park C.M. Competitive inhibition of transcription factors by small interfering peptides. Trends Plant Sci. 2011a;16(10):541-549. DOI 10.1016/j.tplants.2011.06.001.

Seo P.J., Kim M.J., Ryu J.Y., Jeong E.Y., Park C.M. Two splice variants of the IDD14 transcription factor competitively form nonfunctional heterodimers, which may regulate starch metabolism. Nat. Commun. 2011b;2:303. DOI 10.1038/ncomms 1303.

Seo P.J., Park M.J., Lim M.H., Kim S.G., Lee M., Baldwin I.T., Park C.M. A self-regulatory circuit of CIRCADIAN CLOCK-ASSOCIATED1 underlies the circadian clock regulation of temperature responses in Arabidopsis. Plant Cell. 2012;24(6):2427-2442. DOI 10.1105/tpc.112.098723.

Seo P.J., Park M.J., Park C.M. Alternative splicing of transcription factors in plant responses to low temperature stress: mechanisms and functions. Planta. 2013;237(6):1415-1424. DOI 10.1007/s00425013-1882-4.

Shahbazian M.D., Grunstein M. Functions of site-specific histone acetylation and deacetylation. Annu. Rev. Biochem. 2007;76:75-100. DOI 10.1146/annurev.biochem.76.052705.162114.

Sheldon C.C., Burn J.E., Perez P.P., Metzger J., Edwards J.A., Peacock W.J., Dennis E.S. The FLF MADS box gene: a repressor of flowering in Arabidopsis regulated by vernalization and methylation. Plant Cell. 1999;11(3):445-458.

Song J., Angel A., Howard M., Dean C. Vernalization - a cold-induced epigenetic switch. J. Cell. Sci. 2012;125(Pt.16):3723-3731. DOI $10.1242 /$ jcs. 084764

Soy J., Leivar P., González-Schain N., Sentandreu M., Prat S., Quail P.H., Monte E. Phytochrome-imposed oscillations in PIF3 protein abundance regulate hypocotyl growth under diurnal light/ dark conditions in Arabidopsis. Plant J. 2012;71(3):390-401. DOI 10.1111/j.1365-313X.2012.04992.x.

Soy J., Leivar P., Monte E. PIF1 promotes phytochrome-regulated growth under photoperiodic conditions in Arabidopsis together with PIF3, PIF4, and PIF5. J. Exp. Bot. 2014;65(11):2925-2936. DOI $10.1093 / \mathrm{jxb} / \mathrm{ert} 465$.

Stafstrom J.P., Ripley B.D., Devitt M.L., Drake B. Dormancy-associated gene expression in pea axillary buds. Cloning and expression of PsDRM1 and PsDRM2. Planta. 1998;205(4):547-552. DOI 10.1007/ s004250050354.

Sun X., Jones W.T., Harvey D., Edwards P.J., Pascal S.M., Kirk C., Considine T., Sheerin D.J., Rakonjac J., Oldfield C.J., Xue B., Dunker A.K., Uversky V.N. N-terminal domains of DELLA proteins are intrinsically unstructured in the absence of interaction with GID1/ gibberellic acid receptors. J. Biol. Chem. 2010;285(15):1155711571. DOI 10.1074/jbc.M109.027011.

Sun X., Xue B., Jones W.T., Rikkerink E., Dunker A.K., Uversky V.N A functionally required unfoldome from the plant kingdom: intrinsically disordered $\mathrm{N}$-terminal domains of GRAS proteins are involved in molecular recognition during plant development. Plant Mol. Biol. 2011;77(3):205-223. DOI 10.1007/s11103-011-9803-z.

Tatematsu K., Ward S., Leyser O., Kamiya Y., Nambara E. Identification of cis-elements that regulate gene expression during initiation of axillary bud outgrowth in Arabidopsis. Plant Physiol. 2005;138(2): 757-766. DOI 10.1104/pp.104.057984.

Uversky V.N., Dunker A.K. Understanding protein non-folding. Biochim. Biophys. Acta. 2010;1804(6):1231-1264. DOI 10.1016/j. bbapap.2010.01.017.

Vaucheret H., Béclin C., Fagard M. Post-transcriptional gene silencing in plants. J. Cell Sci. 2001;114(Pt.17):3083-3091.

Verhage L., Angenent G.C., Immink R.G. Research on floral timing by ambient temperature comes into blossom. Trends Plant Sci. 2014; 19(9):583-591. DOI 10.1016/j.tplants.2014.03.009.

Wang W., Vinocur B., Shoseyov O., Altman A. Role of plant heatshock proteins and molecular chaperones in the abiotic stress response. Trends Plant Sci. 2004;9(5):244-252. DOI 10.1016/j.tplants. 2004.03.006.

Wenkel S., Emery J., Hou B.H., Evans M.M., Barton M.K. A feedback regulatory module formed by LITTLE ZIPPER and HD-ZIPIII genes. Plant Cell. 2007;19(11):3379-3390. DOI 10.1105/tpc.107. 055772 .

Wood M., Rae G.M., Wu R.M., Walton E.F., Xue B., Hellens R.P., Uversky V.N. Actinidia DRM1 - an intrinsically disordered protein whose mRNA expression is inversely correlated with spring budbreak in kiwifruit. PLoS One. 2013;8(3):e57354. DOI 10.1371/ journal.pone.0057354.

Yamashino T., Nomoto Y., Lorrain S., Miyachi M., Ito S., Nakamichi N., Fankhauser C., Mizuno T. Verification at the protein level of the PIF4-mediated externalcoincidence model for the temperature-adaptive photoperiodic control of plant growth in Arabidopsis thaliana. Plant Signal. Behav. 2013;8(3):e23390. DOI 10.4161/psb. 23390.

Zhang J.Z., Li Z.M., Mei L., Yao J.L., Hu C.G. PtFLC homolog from trifoliate orange (Poncirus trifoliata) is regulated by alternative splicing and experiences seasonal fluctuation in expression level. Planta. 2009;229(4):847-859. DOI 10.1007/s00425-008-0885-z.

Zhang X.N., Wu Y., Tobias J.W., Brunk B.P., Deitzer G.F., Liu D. HFR1 is crucial for transcriptome regulation in the cryptochrome 1-mediated early response to blue light in Arabidopsis thaliana. PLoS One. 2008;3(10):e3563. DOI 10.1371/journal.pone.0003563.

\section{ORCID ID}

A.O. Vyacheslavova orcid.org/0000-0003-0620-1172

I.A. Abdeeva orcid.org/0000-0002-6921-992X

S.A. Bruskin orcid.org/0000-0003-0653-7418 